\title{
Fatal Subarachnoid Hemorrhage due to Intravascular Adrenaline Absorption
}

\author{
Sonia Bansal ${ }^{1}$ Ganne S. Umamaheswara Rao ${ }^{1}$ Seham Syeda ${ }^{1} \quad$ Rohini M. Surve ${ }^{1}$ \\ ${ }^{1}$ Department of Neuroanaesthesia and Neurocritical Care, National \\ Address for correspondence Sonia Bansal, MD, DNB, PDF, \\ Institute of Mental Health and Neurosciences, Bengaluru, \\ Karnataka, India \\ Department of Neuroanaesthesia and Neurocritical Care, National \\ Institute of Mental Health and Neurosciences, Bengaluru 560029, \\ Karnataka, India (e-mail: itz.sonia77@gmail.com).
}

J Neuroanaesthesiol Crit Care 2021;8:130-132.
Abstract
Keywords
- adrenaline
- intravascular
- subarachnoid hemorrhage
- pulmonary edema

Vasoconstrictors are commonly administered with local anesthetics (LAs) to decrease intraoperative bleeding. However, inadvertent systemic absorption of adrenaline is not uncommon and is associated with significant hemodynamic consequences and arrhythmias, which are usually inconsequential. We report a case of suspected intravascular adrenaline absorption in a 1-year-old girl with craniosynostosis, which led to subarachnoid hemorrhage, herniation, and death.

\section{Introduction}

The use of combined vasoconstrictor and local anesthetic (LA) infiltration to decrease intraoperative bleeding is common. Accidental intravascular adrenaline absorption can have significant hemodynamic adverse effects. There are reports of malignant arrhythmias, cardiac failure, and even cardiac arrest in patients with and without neurological diagnosis who have recovered without sequelae. ${ }^{1-3}$ We report a case where systemic adrenaline absorption resulted in critical intracerebral insult which proved fatal.

\section{Case Report}

A 7-month-old female child presented with an abnormal head (tower) shape since birth with no other complaints. She had hypertelorism and her head circumference was 85th percentile with mild motor delay. The child had a premature fusion of sagittal, coronal, and lambdoid sutures, resulting in turricephaly. Magnetic resonance imaging (MRI) showed platybasia, prominent lateral ventricles with small posterior fossa, and tonsillar herniation $13 \mathrm{~mm}$ below foramen magnum. She underwent a foramen magnum decompression, $C_{1}$ arch excision, and posterior fossa remodeling uneventfully and was planned for anterior cranial fossa remodeling later.

Published online April 13, 2020
DOI https://doi.org/

$10.1055 / \mathrm{s}-0040-1708564$ ISSN 2348-0548.
At 1 year of age (weight $8 \mathrm{~kg}$ ), she came for bilateral orbitofrontal advancement. Her preoperative computed tomography (CT) scan was normal ( - Fig. 1A). Anesthesia was induced with fentanyl, thiopentone, and atracurium, and her trachea was intubated with a 5-mm uncuffed endotracheal tube. Anesthesia was maintained with $\mathrm{O}_{2}$, air, and sevoflurane. Invasive blood pressure monitoring was conducted. Prior to making a surgical incision, lignocaine with adrenaline (40 $\mathrm{mg}$ of lignocaine and $10 \mu \mathrm{g}$ of adrenaline [ $2 \mathrm{~mL}$ of $1: 200,000$ diluted to $8 \mathrm{ml}$, i.e., $1: 800,000]$ ) was infiltrated into the incision site. Within 15 seconds of infiltration, blood pressure (BP) increased to 180/110 $\mathrm{mm} \mathrm{Hg}$ and heart rate (HR) decreased from 110 to 70 beats/min. This was followed by tachycardia (HR $>140-150$ beats/min). Supplemental fentanyl $15 \mu \mathrm{g}$ and propofol $20 \mathrm{mg}$ were administered to deepen the plane of anesthesia. However, tachycardia continued and there was a drop in $\mathrm{EtCO}_{2}$ and BP $(54 / 38 \mathrm{~mm} \mathrm{Hg}$ ) and increase in airway pressure from $18 \mathrm{~mm}$ $\mathrm{Hg}$ to $27 \mathrm{~mm} \mathrm{Hg}$. On auscultation, coarse crepitations were heard and patient had pink frothy secretions. Arterial blood gas analysis revealed a $\mathrm{PaO}_{2} / \mathrm{FiO}_{2}$ ratio of 100 . A diagnosis of pulmonary edema was made. $\mathrm{FiO}_{2}$ was increased to $1.0,5 \mathrm{~cm} \mathrm{H}_{2} \mathrm{O}$ PEEP was added, and $5 \mathrm{mg}$ furosemide, $1.5 \mathrm{mg}$ of morphine, and $3.0 \mathrm{mg}$ mephentermine were administered. With these measures, oxygen saturation was maintained $>95 \%$. However, an ST depression was seen on ECG. In view of refractory (c) 2020. Indian Society of Neuroanaesthesiology and Critical Care. This is an open access article published by Thieme under the terms of the Creative Commons Attribution-NonDerivative-NonCommercial-License, permitting copying and reproduction so long as the original work is given appropriate credit. Contents may not be used for commercial purposes, or adapted, remixed, transformed or built upon. (https://creativecommons.org/licenses/by-nc-nd/4.0/).

Thieme Medical and Scientific Publishers Pvt. Ltd. A-12, 2nd Floor, Sector 2, Noida-201301 UP, India 
hypotension, noradrenaline infusion was started. Airway pressures slowly improved and BP increased to $95 / 50 \mathrm{~mm} \mathrm{Hg}$ with noradrenaline infusion. Surgery was abandoned and the patient was shifted to ICU for further management.

In the ICU, after reversal of the neuromuscular blockade, the patient's Glasgow coma scale (GCS) was $\mathrm{E}_{1} \mathrm{~V}_{\mathrm{t}} \mathrm{M}_{1}$ and pupils were dilated and did not react to light. An echocardiogram showed dilated left ventricle which was poorly contracting. Patient continued to be hypotensive, requiring additional dopamine, dobutamine, and adrenaline infusion. There were no crepitations and chest X-ray was clear. A CT scan of the brain showed diffuse brain edema and subarachnoid hemorrhage (SAH) ( - Fig. 1B). An external ventricular drain (EVD) was inserted to drain the cerebrospinal fluid (CSF) and reduce the intracranial pressure. Ten $\mathrm{mL}$ of CSF could be drained from this EVD. There was no further neurological improvement and the patient finally succumbed on the fourth day.

\section{Discussion}

The temporal sequence of events in this case suggest a high-probability of intravascular adrenaline absorption being responsible for severe hypertension (HTN) and tachycardia in the early phases. The initial brief bradycardia could be reflex consequent upon HTN. The other possible cause of bradycardia could be that sudden and severe HTN led to SAH which caused a sudden increase in intracranial pressure (ICP) and herniation. The sympathetic surge associated with SAH would have later led to tachycardia. The tachycardia and hypotension can also be due to direct effects of systemic intravascular adrenaline. Adrenaline is known to cause myocardial stunning and acute cardiac failure (as was seen in the echocardiogram of this patient). As this occurred very early during the complication, cardiac failure may be responsible for causing pulmonary edema. It is also possible that the pulmonary edema is neurogenic in origin as a consequence of SAH.
Vasoconstrictors such as adrenaline are usually administered with LA to decrease bleeding (especially in children) during surgery. Although subcutaneous epinephrine is safe, inadvertent intravascular absorption of epinephrine can cause severe HTN, tachycardia and even malignant arrhythmias such as ventricular tachycardia and ventricular fibrillation, leading to cardiac arrest. ${ }^{1}$ Therefore, the safe use of adrenaline warrants certain precautions. The dose of adrenaline for subcutaneous infiltration needs to be reduced with inhalational agents as they can sensitize the myocardium to adrenaline. Arrythmogenic potential is higher for halothane (dose of adrenaline is $1 \mu \mathrm{g} / \mathrm{kg}$ ) than for isoflurane or desflurane. ${ }^{4}$ Epinephrine less than $7 \mu \mathrm{g} / \mathrm{kg}$ has been found to be safe with desflurane and isoflurane as anesthetics. The smallest dose of epinephrine to elicit three or more premature ventricular contractions within $5 \mathrm{~min}$ utes of its administration has been reported to be $7 \mu \mathrm{g} / \mathrm{kg}$ for desflurane and $7.3 \mu \mathrm{g} / \mathrm{kg}$ for isoflurane. ${ }^{5}$ Arrythmogenic potential is similar for isoflurane and sevoflurane. ${ }^{6}$ Addition of LA increases the safe dose by $50 \%$. Also, higher concentration of adrenaline $(>1 / 100,000$ or $1 / 200,000)$ and using it alone (without combining it with LA) increases the likelihood of side effects. ${ }^{2}$ Hypoxia and hypercarbia may enhance the possibility of arrhythmias with adrenaline. ${ }^{7}$ In our case, the dose of adrenaline used was $1.25 \mu \mathrm{g} / \mathrm{kg}$ in a dilution of $1 / 800,000$ and along with LA, which is well below the recommended dose. In the earlier reports with a similar complication, there was no mortality ${ }^{1-3}$ However, in this patient, the hemodynamic effects of epinephrine were poorly tolerated. This is because patients with multisutural complex craniosynostosis are likely to have intracranial hypertension (ICHT) due to multifactorial etiology. The causes for such ICHT are as follows: (1) Craniocephalic disproportion, (2) venous hypertension due to impedance to venous outflow and consequent hydrocephalus, (3) obstructive sleep apnea, and (4) Arnold Chiari malformation. ${ }^{8}$ Although the current patient underwent foramen magnum decompression, the decrease in ICP would have been only partial and patient would still

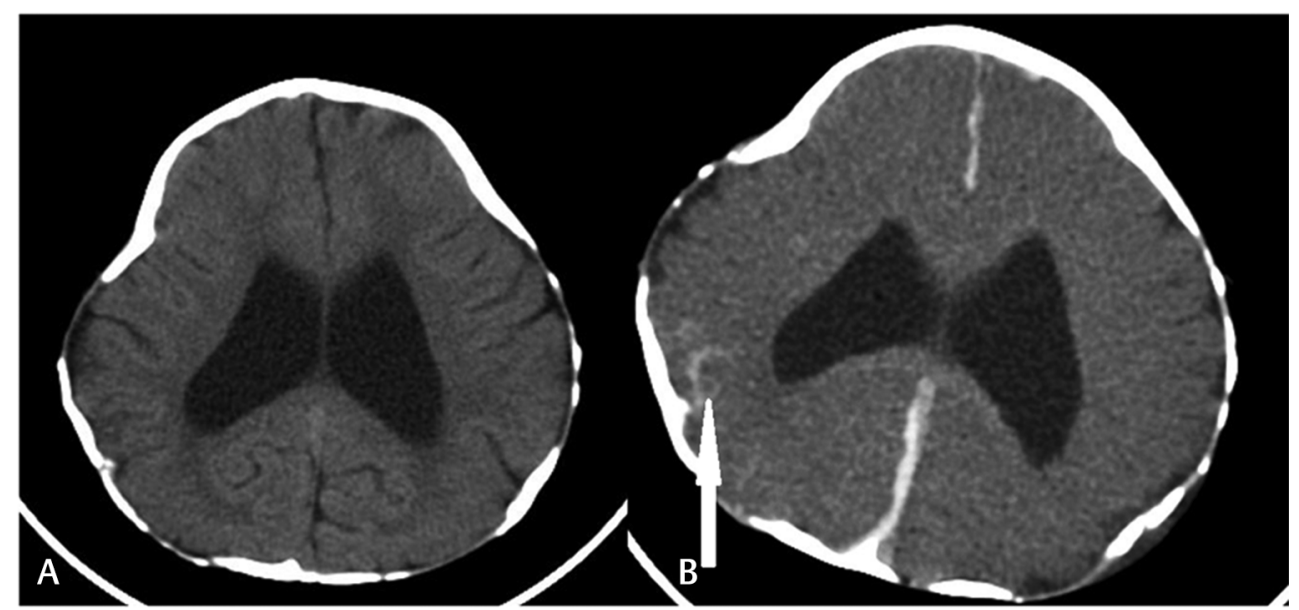

Fig. 1 (A) Preoperative CT scan of the brain. (B) CT scan of the brain showing diffuse brain edema, effacement of sulci, subdural hemorrhages along the falx and tent along with subarachnoid hemorrhage in the left parietal area. CT, computed tomography. 
be having ICHT due to other contributing causes. In such a patient, SAH caused by a sudden increase in BP would have further increased the ICP. Moreover, in pediatric patients, the autoregulation may not have been fully developed and the latency for autoregulation may be increased. ${ }^{9}$ In pediatric patients, autoregulation curve is steeper on both sides, below the lower limit, and also above the upper limit of autoregulation. Hence, they poorly tolerate either hypotension or HTN. Even transient episodes of HTN can lead to ICHT in small children. At 1 year of age, as in this case, autoregulation is unlikely to be completely developed. This might be the reason for systemic HTN caused by adrenaline to increase the cerebral blood flow and rupture of the cerebral blood vessels, causing SAH.

Venous hypertension due to venous outflow impedance is also not uncommon in patients with craniosynostosis. Inadvertent intravascular injection of adrenaline might have raised the venous pressure and caused the venous bleed.

Keeping in mind the age of the patient combined with the presence of trans-osseous venous collaterals and perturbed venous drainage, there is an increased risk of massive intraoperative blood loss during skin dissection and bone removal, which justifies the need for adrenaline infiltration. However, one should be very cautious in using epinephrine in patients with an intracranial pathology, as it can lead to a devastating complication. Need for repeated aspirations and slow injection cannot be overemphasized.

\section{Conflict of Interest}

None declared.

\section{References}

1 Pawar SC, Patil SS, Jagtap SR, Deolokar S. Cardiac arrest after submucosal infiltration with lignocaine $2 \%$-epinephrine in nasal surgery: A case report. S Afr J Anaesthesiol Analg 2009;15:29-31

2 Gupta N, Gupta V. Life-threatening complication following infiltration with adrenaline. Indian J Anaesth 2014;58(2):225-227

3 Bae JY, Woo CH, Kim SH, Kwak IS, Mun SH, Kim KM. Cardiovascular crisis after small dose local infiltration of epinephrine in patient with asymptomatic subarachnoid hemorrhage -A case report-. Korean J Anesthesiol 2010;59(Suppl) :S53-S57

4 Johnston RR, Eger EI II, Wilson C. A comparative interaction of epinephrine with enflurane, isoflurane, and halothane in man. Anesth Analg 1976;55(5):709-712

5 Moore MA, Weiskopf RB, Eger EI II, Wilson C, Lu G. Arrhythmogenic doses of epinephrine are similar during desflurane or isoflurane anesthesia in humans. Anesthesiology 1993;79(5):943-947

6 Navarro R, Weiskopf RB, Moore MA, et al. Humans anesthetized with sevoflurane or isoflurane have similar arrhythmic response to epinephrine. Anesthesiology 1994;80(3):545-549

7 Katz RL, Katz GJ. Surgical infiltration of pressor drugs and their interaction with volatile anaesthetics. Br J Anaesth 1966; 38(9):712-718

8 Ghali GZ, Zaki Ghali MG, Ghali EZ, et al. Intracranial venous hypertension in craniosynostosis: mechanistic underpinnings and therapeutic implications. World Neurosurg 2019;127:549-558

9 Udomphorn Y, Armstead WM, Vavilala MS. Cerebral blood flow and autoregulation after pediatric traumatic brain injury. Pediatr Neurol 2008;38(4):225-234 